\title{
E -Content Development in Higher Education: An Essential Criteria for Post Pandemic Quality Education
}

\author{
Srutirupa Panda \\ Nabakrushna Choudhury College of Teacher Education, Angul, Odisha, India
}

\begin{abstract}
Higher education is an essential phase of learning that prepares competent and skillful youth and manpower for country. However due to COVID 19 outbreaks, this system of education get affected negatively in India. Face to face mode of education is not possible due to lock down and closing of educational institutions throughout the country. In this concerns, there is a great need of preparing e contents in various subjects by expert faculties of various colleges and universities in order to maintain the quality of higher education. The present paper tries to explain importance of e content development in higher education system and explore various tool and techniques that can be utilized to develop e content for quality higher education system.
\end{abstract}

Keywords:E - Content, Higher Education, Pandemic Quality

\section{INTRODUCTION}

Higher education is one of the significant stages in the whole process of learning at formal, informal and non-formal channels of education. It is the phase where students learn desired stream with specialization in a wider context of subjects. Higher education deals with most complex, abstract concepts and principles having research oriented approaches that provides greater opportunities to the citizens of the country to bring growth, development and prosperity to the nation. The skilful manpower of the country is dependent on the success of higher education and quality of higher education determines the competence of future citizens in terms of constructing one developed nation. The success of higher education is affected by several factors including quality and quantity issue. To achieve great success in the field of higher education it is necessary to merge latest technology and raise the quality in the whole process of teaching learning at this significant level.

With the outbreak of Covid 19 pandemic, higher education of India has affected a lot. Students could not attend face to face mode of interaction inside the college or universities as the institutions were shut down during the period.

Over the past weeks, education officials have been forced to cancel classes and close the doors to campuses across the world in response to the growing coronavirus outbreak. In addition, US institutions have switched classes to online learning, cancelled spring break trips and students studying abroad in China, Italy and South Korea have been encouraged to return home to complete their studies.

While class closures, dips in enrolment at the beginning of a new semester and cancellations may be temporary, it's hard to foresee whether the novel coronavirus will result in long-term disruption to the higher education system.

As per the Ministry of Human Resource Development (MHRD), there are 993 universities, 39931, 10725 stand alone institutions listed in its portal which is meant for education ( Kumar 2030). Hence it is a great challenge to higher education deal with the learning demands of students of higher education.In this connection there is a great need of use of technology to convert information into knowledge. In this context e content development can be considered as one of the important tool to support and encourage quality higher education .Jena (2020) highlighted some of the major impact of Covid 19 on higher education. He emphasized that many new modes and trends of learning are necessarily emerged in order to cope up with the impact of covid19 on higher education. In this concern e content development can be considered as one of the best practices to encourage learning at higher education.

\section{What is E Content?}

E content refers to electronic content of teaching learning or digital content delivered through network based electronic devices like computer, smart phone, laptop etc. Oxford dictionary defines e content as digital texts and images designed to display in web pages. E-content is basically a package that satisfies the conditions like minimization of distance, cost effectiveness, user friendliness and adaptability to local conditions'.(Saxena 2011).

E content is getting lots of attentions during post pandemic period due to its various unique characteristics.Those are provisions of

- $\quad$ flexibility in teaching and learning 
DOI: 10.17148/IARJSET.2021.8943

- $\quad$ Flexibility with respect to pace of learning

- Universal by nature which means it can break geographical, social barriers

- $\quad$ It can cover wide variety of learners with diverse needs, social streams, previous knowledge and experience and skill level.

- Various electronic media can be used to redistribute E content universally

- $\quad$ E content can be prepared in any subject of studies by experts

- $\quad$ It can be accessible to all needful learners teaches.

- It can be denoted as quick learning resource for unlimited number of learners.

- $\quad$ Educational information can make e learning seven tool to organize their educational programmes.

- $\quad$ E content can be described as a significant dimension for open and distance learning education.

\section{Types of E Content}

In this digital world there are varieties of e content available such as :

- Slides

- Online quizzes

- Videos

- $\quad$ Podcasts

- Dialogues simulation, discussion forum

- Interactive videos

- $\quad$ E books

- Virtual reality and augmented reality, simulation

- $\quad$ E games

\section{Designing and Development of E-content}

E content development leads to creation of an inclusive knowledge society having vast information within them. In this society each one have the facility to prepare, get, share and use information for their benefits .However as an pre requisite each e contain package must be qualitative enough to serve the society as a virtual teacher.

Designing and developing e content mainly depend upon the

$\begin{array}{ll}\text { - } & \text { Need of Learners } \\ \text { - } & \text { Nature of Learners } \\ \text { - } & \text { Type of content concepts } \\ \text { - } & \text { Standard of learning process } \\ \text { - } & \text { Goals of Educational activities } \\ \text { - } & \text { Hardware and software technology } \\ \text { - } & \text { Expertise of teachers } \\ & \text { E content design methods or models }\end{array}$

\section{INSTRUCTIONAL DESIGN MODELS FOR E CONTENT DEVELOPMENT}

Various instructional design models are available according to our requirements. Most of the models involve the process of analysing the learner needs and goals of the instructional material development, development of a delivery system and content, pilot study of the material developed, implementation, evaluating, refining the materials etc. In designing and development of E-content we have to adopt one of the instructional design models based on our requirements. Before understanding the designing and development of e-content it is essential to understand the meaning of instructional design.

According to Wikipedia 'instructional design is the practice of creating instructional experiences which make the acquisition of knowledge and skill more efficient, effective and appealing. The process broadly consists of determining the current status of learner understanding, defining the end goal of the instructional material and creating some 'intervention' to assist the transition. This systematic approach provides a step by step process for the analysis of the learners' needs, the design and development of the material'.

Most common and popular model used for creating instructional materials is the ADDIE model. This abbreviation stands for the five phases involved in the model. They are analyze, design, develop, implement and evaluate. This model is initially developed by Florida State University to explain the processes involved in the formulation of an instructional systems development (ISD) program for military inter-service training. ISD was meant for training individuals to do a particular job. This can also be applied to any inter-service curriculum development activity. Originally the model 


\section{DOI: 10.17148/IARJSET.2021.8943}

contained several steps under its five original phases (analyze, design, develop, implement and evaluate). Over the years the steps were revised and finally the model itself became more dynamic and interactive.

Analysis: It is the first phase of this model meant for examining the suitability of the e-content to be developed. It is related to analyzing the learning needs, context, learner, task and content. Analyzing the learning needs is identifying the needs from the perspective of different learners, teachers, subject experts, practitioner, policy makers etc. Needs are to be clearly stated.

- Contextual analysis is collecting data related to the context of learning such as learning environment. Whether the e-content developed is for the individual or group, formal or informal, facilitated or self-learning etc.

- Learner analysis is collecting data related to learners academic levels and attributes such as skills, motivation, visual literacy, language competency, learning styles etc. That is nothing but preparing the learner profile. It helps to know about the learner.

- Task analysis is stating the purposes of developing the e-content. Deciding whether that is developed for educating, training, creating awareness, developing skills etc.

- Content analysis is nothing but preparing a content outline. Good content comprehension is required before designing and developing content. It includes verifying the content with respect to cognitive appropriateness, factual accuracy, completeness etc. It also includes classifying the content into facts, concepts, principles, processes and procedures.

Design: It is concerned with defining the learning objectives, structuring the content logically, specifying the instructional and evaluation strategies, and preparing for visual and technical design.

- Learning objectives are to be defined in clear, realistic and measurable terms. Learning objectives are the statements that describe what the learner will be able to do at the end of the course or program. Learning objectives should specify performance and communicate their purposes. Prepare a detailed content outline in which content is thoroughly analyzed and logically organized. Content is to be structured logically following simple to complex, known to unknown, concrete to abstract, general to specific etc.

- Instructional strategies are to be stated clearly. Depending on the learning style and nature of the content we have to decide the appropriate instructional strategy. Appropriate media mix that is combination of audio, video, graphics, animation; simulation etc is to be decided.

- Learner evaluation strategies such as practice, computer marked or tutor marked assessments, pretest, posttest, remedial tests etc are to be specified. We have to decide about the formative and summative assessments. Before developing the content for the selected course review the proposed learning objectives. Make sure that content, assessment tests and exercises match the objectives stated. Provide the information and knowledge required to meet the learning objectives.

Development: It is related to the creation of story board. Story board is nothing but scripting the entire course content. The term 'story board' is taken from film production. In a movie it indicates the visual representation of the various scenes. In e-content development the story board describes step by step script of the final outcome of the e-content i.e. story board is created to provide a blue print of the course with each and every detail along with the content notes. The story board is created based on the objectives and instructional strategies. Here the developers create and assemble the content assets and learning objects. Programming and integration of all media elements into a cohesive multimedia package are the part of this phase.

Implement: In the implementation phase, materials are distributed to learners. A comprehensive implementation strategy document is developed. This document should cover the course curriculum, learning outcomes, method of delivery in terms of hard ware and soft ware requirements and testing procedures. Ensure that the web site is functional if the material is on the web site.

Evaluation: The evaluation phase consists of two parts i.e. Formative and summative evaluation. Formative evaluation is present in each stage of the ADDIE process. Summative evaluation determines the adequacy of the distributed materials in achieving the course objectives. Material is to be revised at all the stages based on the feedback received.

Now, let us learn the main features of some popular alternative models.

1. Dick and Carey Design Model

- Starts by identifying instructional goals

- $\quad$ Ends with summative evaluation

- Focuses on specific objectives

- Similar to that of software engineering. 


\section{International Advanced Research Journal in Science, Engineering and Technology}

Vol. 8, Issue 9, September 2021

DOI: 10.17148/IARJSET.2021.8943

\section{Hannafin and Peck Design Model}

The Hannafin Peck model (1987) uses a three phase process

Phase 1: perform a needs assessment

Phase 2: design

Phase 3: develop and implement instruction

(Note: All the phases involve a process of evaluation and revision)

\section{Knirk and Gustafson Design Model}

The Knirk and Gustafson model (1986) also uses a three stage process:

Stage 1: identify the problem and set instructional goals

Stage 2: design and develop objectives, set instructional objectives and specify strategies

Stage 3:develop materials

\section{QUALITY STANDARDS OF E-CONTENT}

E-content standards are rules that most e-content developers should abide by. Standards are engineering or technical specifications that help e-content developers to establish uniformity. The different kinds of standards are mandatory, voluntary and defacto. Mandatory means one should comply, voluntary is one may or may not follow and defacto which are well established common practices but may not be formally published. Ensuring the high quality of the e-content is concerned with creating, communicating, and maintaining consistent development standards. Writing and textual, graphical and page design, questions and test, interactivity and audio/video standards and guidelines are to be ensured before finalizing. With respect to the quality of the e-content it should be correct, adaptive, communicative, interactive, reflexive, explorative, standardized etc.

Formal standards bodies such as the World Wide Web Consortium (W3C), the Internet Engineering Task Force (IETF), and International Organization for Standardization (ISO) etc publish the electronic standards. W3C is international standards organization for World Wide Web.E-learning industry follows certain standards for integration of course ware. There are several standards available today for content integration and interoperability. International bodies generally design and publish the standards.

According to International Organization for Standardization(ISO) standards can be defined as "documented agreements containing technical specialization or other precise criteria to be used consistently as rules, guidelines or definitions of characteristics to ensure that materials, products, processes and services are fit for their purpose.”

Share-able Content Object Reference Model (SCORM): It is a powerful tool. Content can be created and used in many different systems. Content can also be used in many situations without modification. It is the most widely used standard in all LMSs. It has applications in general usage as well as defense related uses.

Aviation Industry CBT Committee (AICC): This was the first standard to be adopted by the e-learning industry. It is still actively used in the aviation industry.

Institute of Electrical and Electronics Engineers (IEEE) IMS Standards: This enables high quality accessible and affordable learning experiences. This standard is mainly used today schools, colleges, universities, government institutions etc.

Instructional Management System Global Learning Consortium (usually referred to as IMS GLC, IMS Global or simply IMS) is a global, nonprofit, member organization that strives in shaping and growing the learning industry through community development of interoperability and adoption practice standards. Their main activity is to develop interoperability standards and adoption practice standards for distributed learning,

\section{CONCLUSION}

E content development is not only helpful for the learner to personalize the learning but it can also be considered as one of the essential teaching learning resource materials. Keeping the needs of the learners different types of e contents can be developed. In this concern teachers needs to be play crucial roles for conducting need assessment, designing learning objectives, creating e contents using latest technologies of software and hardware is very significant Further quality of such e contents must be of up to mark. 


\section{International Advanced Research Journal in Science, Engineering and Technology}

Vol. 8, Issue 9, September 2021

DOI: 10.17148/IARJSET.2021.8943

\section{REFERENCES}

1. DNS Kumar (29 April 2020). Impact of COVID-19 on Higher Education. Retrieved on May 25, 2020 from https://www.highereducationdigest.com/impact-ofcovid-19-on-higher-education/

2. Pravat Ku Jena. Challenges and Opportunities created by Covid-19 for ODL: A case study of IGNOU. International Journal for Innovative Research in Multidisciplinary Filed. 2020a;6(5):217

3. Wikipedia. Covid-19 Pandemic in India. Retrieved on May 20, 2020 from https://en.wikipedia.org/wiki/COVID19_pandemic_in_India

4. Wikipedia, Education in India Retrieved on May 24, 2020. from https://en.wikipedia.org/wiki/Education_in_India

5. Mehak Sharma; Kuldeep Kaur Grewal; Mohua Khosla. "A Review: Planning in the Field of Inclusive Education". International Research Journal on Advanced Science Hub, 3, Special Issue 6S, 2021, 170-176. doi: 10.47392/irjash.2021.185

6. Sarbjot kaur. "Academic Achievement and Creativity among 10th Class Students". International Research Journal on Advanced Science $H u b, 3$, Special Issue ICARD-2021 3S, 2021, 158-161. doi: 10.47392/irjash.2021.085 